\title{
ARTICLE \\ Cigarette smoke-induced cell death of a spermatocyte cell line can be prevented by inactivating the Aryl hydrocarbon
} receptor

\author{
P Esakky ${ }^{1,2}$, DA Hansen ${ }^{1}$, AM Drury ${ }^{1,2}$, A Cusumano $^{2}$ and KH Moley ${ }^{2}$
}

Cigarette smoke exposure causes germ cell death during spermatogenesis. Our earlier studies demonstrated that cigarette smoke condensate (CSC) causes spermatocyte cell death in vivo and growth arrest of the mouse spermatocyte cell line (GC-2spd(ts)) in vitro via the aryl hydrocarbon receptor (AHR). We hypothesize here that inactivation of AHR could prevent the CSC-induced cell death in spermatocytes. We demonstrate that CSC exposure generates oxidative stress, which differentially regulates mitochondrial apoptosis in GC-2spd(ts) and wild type (WT) and AHR knockout (AHR-KO) mouse embryonic fibroblasts (MEFs). SiRNA-mediated silencing of $\mathrm{Ahr}$ augments the extent of CSC-mediated cellular damage while complementing the AHR-knockout condition. Pharmacological inhibition using the AHR-antagonist (CH223191) modulates the CSC-altered expression of apoptotic proteins and significantly abrogates DNA fragmentation though the cleavage of PARP appears AHR independent. Pretreatment with $\mathrm{CH} 223191$ at concentrations above $50 \mu \mathrm{M}$ significantly prevents the CSC-induced activation of caspase-3/7 and externalization of phosphatidylserine in the plasma membrane. However, MAPK inhibitors alone or together with $\mathrm{CH} 223191$ could not prevent the membrane damage upon CSC addition and the caspase-3/7 activation and membrane damage in AHR-deficient MEF indicates the interplay of multiple cell signaling and cytoprotective ability of AHR. Thus the data obtained on one hand signifies the protective role of AHR in maintaining normal cellular homeostasis and the other, could be a potential prophylactic therapeutic target to promote cell survival and growth under cigarette smoke exposed environment by receptor antagonism via $\mathrm{CH} 223191$-like mechanism. Antagonist-mediated inactivation of the aryl hydrocarbon receptor blocks downstream events leading to cigarette smoke-induced cell death of a spermatocyte cell line.

Cell Death Discovery (2015) 1, 15050; doi:10.1038/cddiscovery.2015.50; published online 26 October 2015

\section{INTRODUCTION}

Habitual smokers have $13 \%$ lower sperm count than nonsmokers. ${ }^{1}$ This is because the 7000 constituents, including 69 proven carcinogens, of cigarette smoke (CS) accumulate in the systemic circulation and seminal plasma and irreversibly impair both the quality and quantity of human spermatozoa. ${ }^{2,3}$ Chronic exposure to CS is toxic to germ cells ${ }^{4,5}$ and results in excessive generation of free oxygen radicals. ${ }^{6}$ Thus, the spermatozoa of cigarette smokers have increased levels of oxidative DNA damage and adducts, chromosomal abnormalities, and oxidized unsaturated fatty acids. ${ }^{7}$

Cigarette smoke condensate (CSC), or tar, consists mainly of dioxins, halogenated and nonhalogenated polycyclic aromatic hydrocarbons (PAHs), and pro-oxidants, ${ }^{8}$ which strongly inhibit meiotic progression of spermatocytes $^{9}$ and stimulate genes involved in the metabolism of PAHs. ${ }^{10} \mathrm{PAHs}$ and the dioxin 2,3,7,8-Tetrachlorodibenzo- $p$-dioxin (TCDD) act through the ligand-dependent transcription factor, aryl hydrocarbon receptor (AHR). ${ }^{11}$ Ge et al. ${ }^{12}$ suggested that PAHs could impair gametogenesis by AHR-mediated suppression of meiosis. In addition, we demonstrated that in vivo exposure to CSC results in spermatocyte cell death and seminiferous tubule disruption. ${ }^{13}$ Furthermore, we reported that $A H R$ is needed for proper seminiferous tubule architecture and sperm development. ${ }^{14}$ However, the role of AHR in apoptosis is unclear; some studies have indicated that AHR activation increases apoptosis, whereas others suggest that it decreases apoptosis. ${ }^{15,16}$ Many of these studies have relied on exogenously activating AHR with TCDD ${ }^{17}$ instead of the complex chemicals found in CS. Nonetheless, studies using AHR-knockout mice indicated that most of the TCDD-induced toxicity is mediated through AHR. ${ }^{18}$

As the mechanistic outcome of exposure to CSC is growth arrest followed by cell death in both in vitro and in vivo spermatocytes as demonstrated by our previous studies and to address the role of AHR in this process, we turned to the spermatocyte cell line $\mathrm{GC}-2 \mathrm{spd}(\mathrm{ts})$. We earlier found that CSC exposure altered the growth of spermatocytes by facilitating a crosstalk between MAPK and AHR-NRF2 pathways. ${ }^{19}$ Here we report that CSC promotes a mitochondrial-based apoptotic pathway in spermatocytes in vitro. CSC-exposed GC-2spd(ts) cells exhibited characteristic features of apoptosis such as altered expression of apoptotic proteins, DNA fragmentation, cleavage of Poly(ADP-ribose) polymerase, activation of executor caspases and externalization of phosphatidylserine on the membrane surface. We found that treating the spermatocytes with the AHR-specific inhibitor $\mathrm{CH} 223191$ significantly blunted the proapoptotic effect of CSC. However, knockdown of $\mathrm{Ahr}$ accompanied with enhanced CSC-mediated

\footnotetext{
${ }^{1}$ Department of Veterans Affairs Medical Center, Washington University School of Medicine, St. Louis, MO, USA and ${ }^{2}$ Department of Obstetrics and Gynecology, Washington University School of Medicine, St. Louis, MO, USA.

Correspondence: KH Moley (moleyk@wustl.edu)

Received 5 September 2015; revised 10 September 2015; accepted 12 September 2015; Edited by A Rufini
} 
apoptosis indicates its endogenous protective role in maintaining tissue homeostasis. Our results provide evidence that development of an AHR inhibitor similar to $\mathrm{CH} 223191$ might provide a useful prophylactic to prevent the complications of exposure to CS and other similar pollutants.

\section{RESULTS}

Cigarette smoke condensate creates oxidative stress in the spermatocyte cell line GC-2spd(ts)

We previously used microscopy to demonstrate that GC-2spd(ts) cells (hereafter referred to as spermatocytes) accumulate reactive oxygen species after six hours of CSC exposure. ${ }^{13}$ To better quantitate this effect, we used flow cytometry to assess the percentage of cells that stained with cellROX, an indicator of cytoplasmic oxidative stress. We found that the percentage of cellROX-positive cells increased significantly upon exposure to $40 \mu \mathrm{g} / \mathrm{ml} \mathrm{CSC}$ (Figures 1a and b). In addition, flow cytometric analysis revealed that the percentage of cells positive for the mitochondrial superoxide indicator mitoSOX increased significantly upon CSC exposure (Figures 1c and d). We next assessed mitochondrial membrane potential by staining control and CSC exposed cells with MitoProbe DiOC2(3). As a monomer, DiOC2(3) emits green fluorescence and, in a reaction driven by the mitochondrial membrane potential, converts to a redfluorescence-emitting dimer. Here we found that CSC did not alter the membrane potential of mitochondria either at one or five hours of exposure (Figures 1e and f). Thus, CSC at $40 \mu \mathrm{g} / \mathrm{ml}$ induces oxidative stress in both the cytoplasm and mitochondria of spermatocytes, but does not alter mitochondrial membrane potential.

CSC-altered expression of BCL2 family members in spermatocytes is independent of AHR.

We next wanted to determine whether CSC exposure affects expression of apoptosis regulators in spermatocytes. Thus, we used flow cytometry to assess expression of the antiapoptotic proteins $\mathrm{BCL} 2$ and $\mathrm{BCL} 2 \mathrm{~L} 1$ and the proapoptotic proteins $B A X$ and $B A D$. We found that exposure to CSC increased the percentage of spermatocytes expressing $B C L 2 L 1$ (Figures 2a and b), BCL2 (Figures 2e and f), BAX (Figures $3 a$ and b), and $B A D$ (Figures $3 e$ and $f$ ). To determine whether these changes a
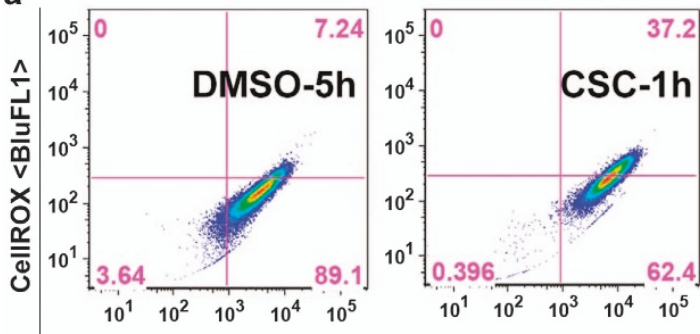

SYBR 14 dye <BluFL4>

c
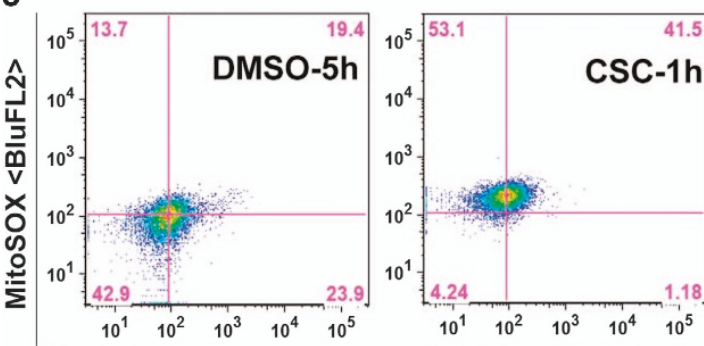

TO-PRO-3 <RedFL1>
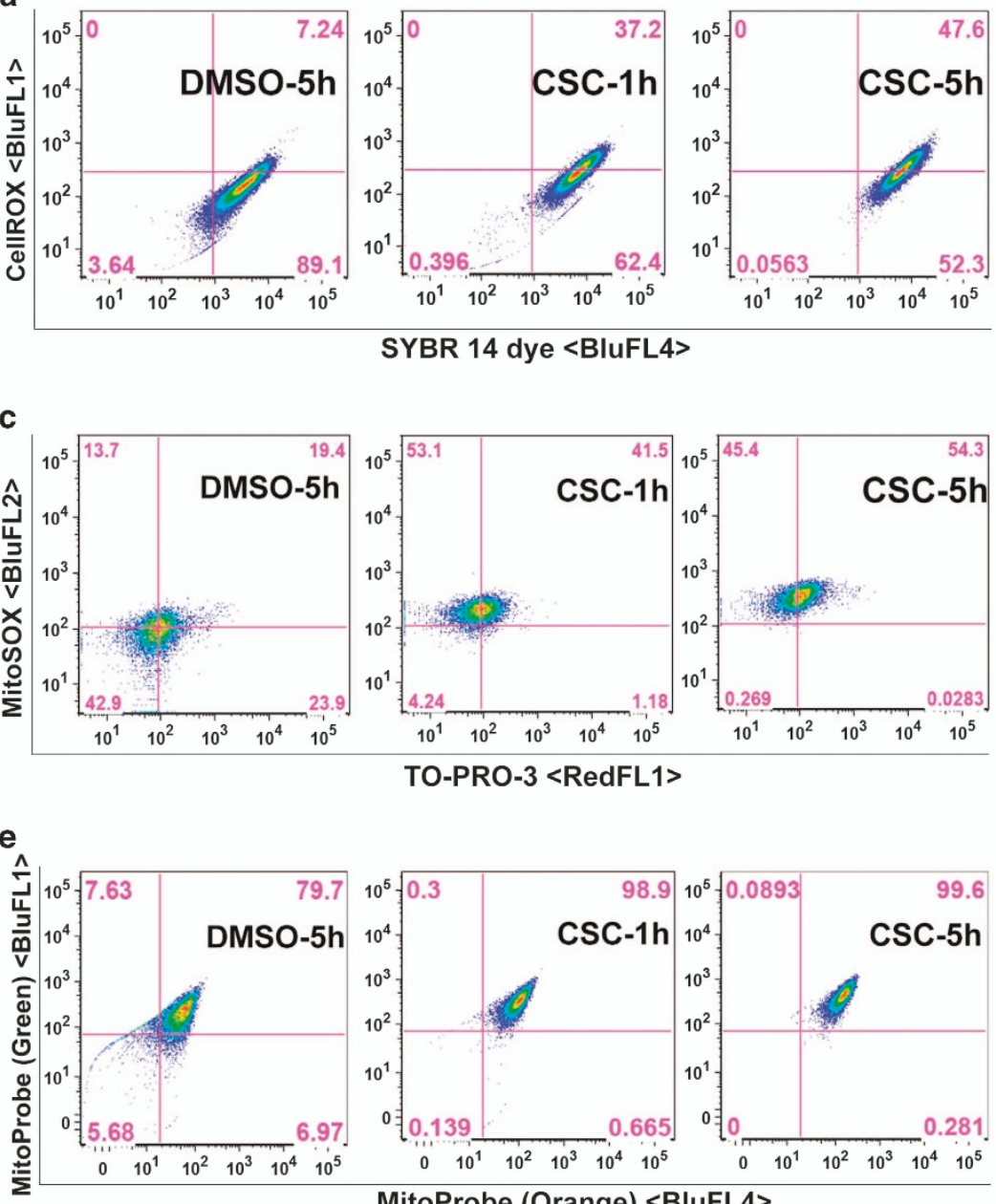

b

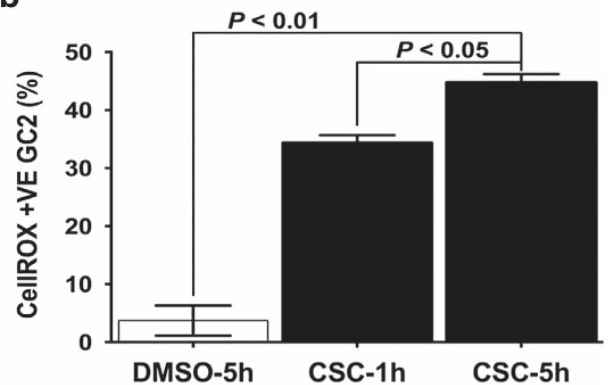

d

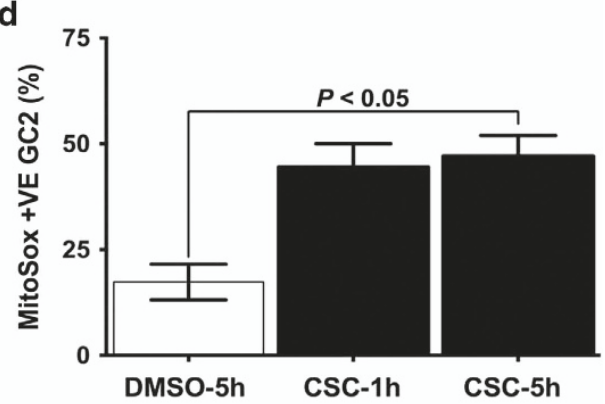

f

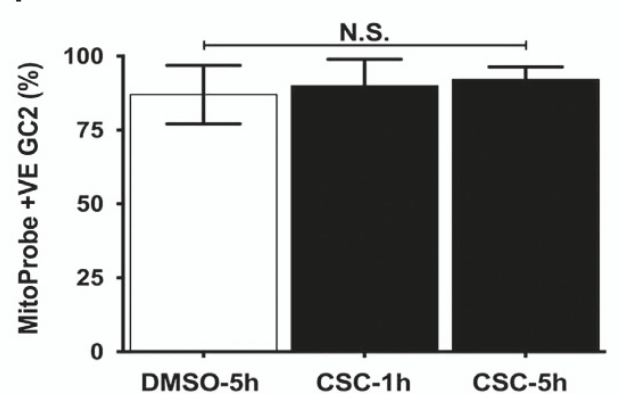

Figure 1. CSC induces oxidative stress but does not alter mitochondrial membrane potential in spermatocytes. (a, c, and e) Representative flow cytometric analyses of spermatocytes exposed to DMSO $(0.1 \%$ for $5 \mathrm{~h})$ or CSC $(40 \mu \mathrm{g} / \mathrm{ml})$ for 1 and $5 \mathrm{~h}$, then stained with (a) cellROX deep red reagent (BluFL1) and counter-stained with viable dye SYBR 14 (BluFL4), (c) mitoSOX superoxide indicator (BluFL1) and counter-stained with viable nuclear dye TO-PRO-3 (RedFL1), or (e) mitoProbe (Green, BluFI1 on y axis; Orange, BluFL4 on $x$ axis). Percentages of double-positive cells are indicated in the upper right quadrants. $(\mathbf{b}, \mathbf{d}$ and $\mathbf{f}$ ). Histograms present the mean percentages of double-positive spermatocytes from three independent experiments, each assayed in triplicate, \pm S.E.M. 
a

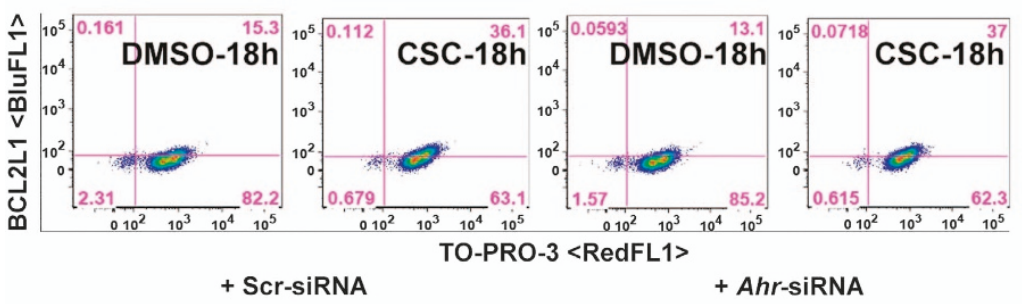

c

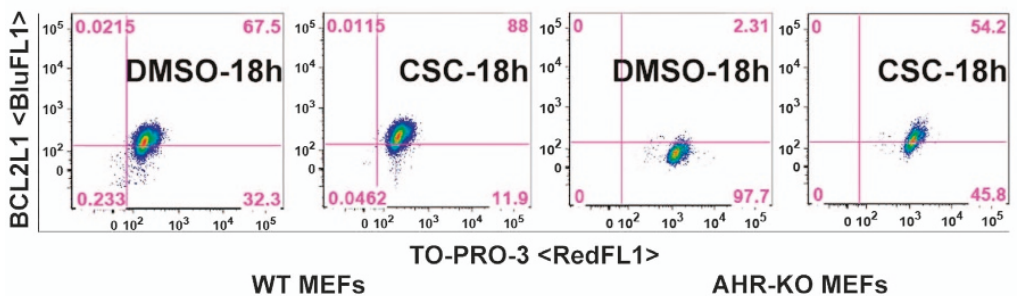

e

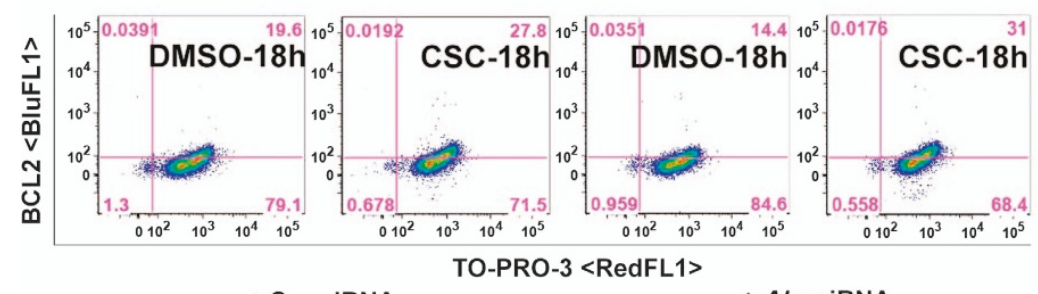

+ Scr-siRNA

+ Ahr-siRNA

g

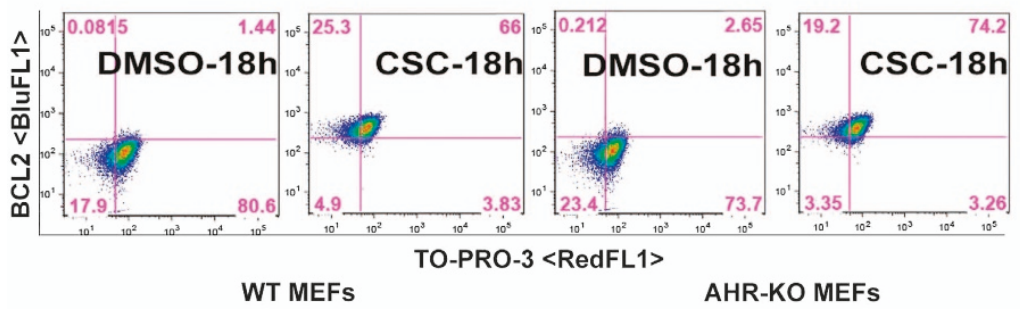

b

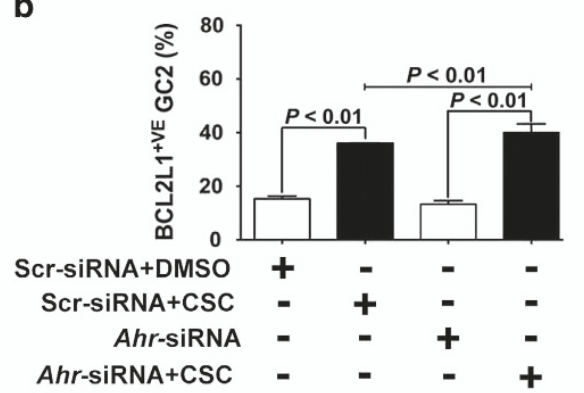

d

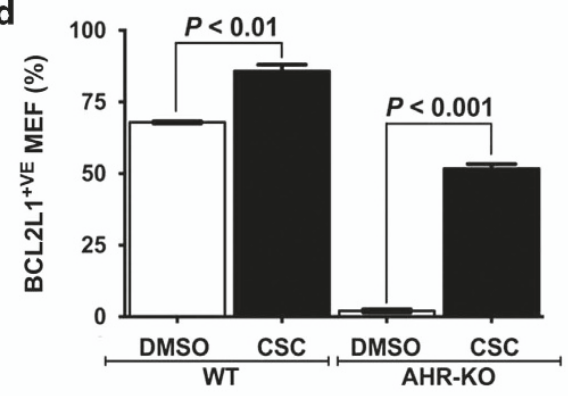

$\mathbf{f}$

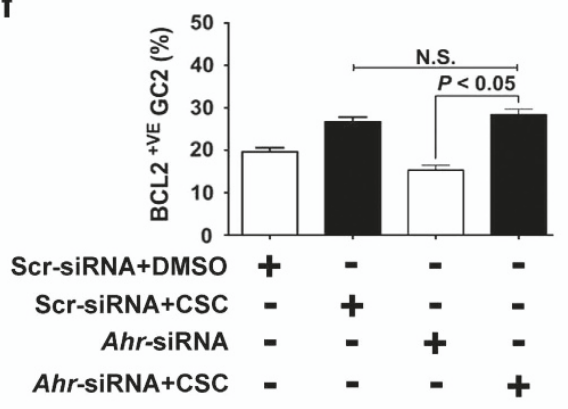

h

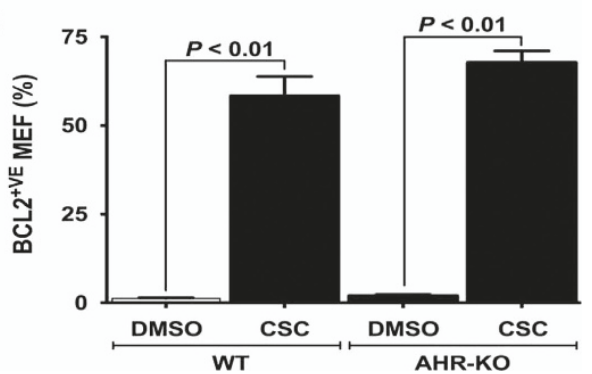

Figure 2. CSC modulates the expression of antiapoptotic proteins. (a, c, e, and g) Representative flow cytometric analyses of (a and e) spermatocytes transfected with scr-siRNA or Ahr-siRNAs and (c and $\mathbf{g})$ WT and AHR-KO MEF cells treated with DMSO or CSC for $18 \mathrm{~h}$ and then stained with (a and $\mathbf{c}$ ) anti-BCL2L1 (BluFL1) or (e and $\mathbf{g}$ ) anti-BCL2 (BluFL1) antibody and counter-stained with TO-PRO-3 (RedFL1). Percentages of double-positive cells are indicated in the upper right quadrants. (b, $\mathbf{d}, \mathbf{f}$ and $\mathbf{h}$ ). Histograms present the mean percentages of doublepositive spermatocytes and MEFs from three independent experiments, each assayed in triplicate, \pm S.E.M.

require AHR, we evaluated Ahr-knock down spermatocytes by siRNA and treated them with CSC. Western blot showed that siRNA suppression has significantly (>70\%) abrogated AHR expression in the spermatocytes (data not shown). However, we noticed that the Ahr knockdown did not prevent any of the CSC-induced gene expression changes in spermatocytes. Because siRNA-mediated knockdown is transient and or Ahr may be incompletely inactivated, we compared the effects of CSC exposure with another different cell type, the mouse embryonic fibroblasts (MEFs) isolated from wild type (WT) and Ahr-knockout (AHR-KO) mice. As in spermatocytes, we found that in MEFs, Ahr was not required for changes in the percentage of cells positive for BCL2L1, BCL2, BAX, and BAD upon CSC exposure (Figures $2 c$, d, $\mathrm{g}, \mathrm{h}$ and $3 \mathrm{c}, \mathrm{d}, \mathrm{g}, \mathrm{h}$ ). These results suggest that CSC-induced oxidative stress activates the mitochondrial pathway of apoptosis in spermatocytes by differentially modifying the expression of apoptotic proteins in an AHR-independent manner.

CSC exposure breaks DNA strands in spermatocytes.

Our previous studies showed that CSC exposure increased spermatocyte DNA damage in vivo and elevated the expression of genes associated with DNA damage in vitro. ${ }^{13,19}$ To determine whether CSC reflects similar effects in the spermatocyte cell line 
a

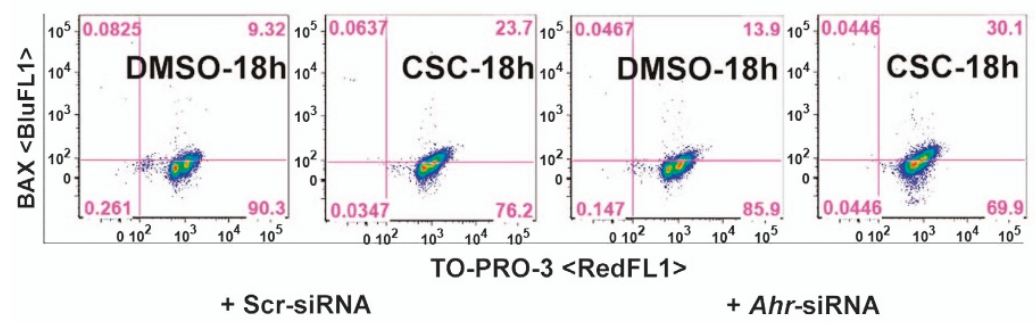

C
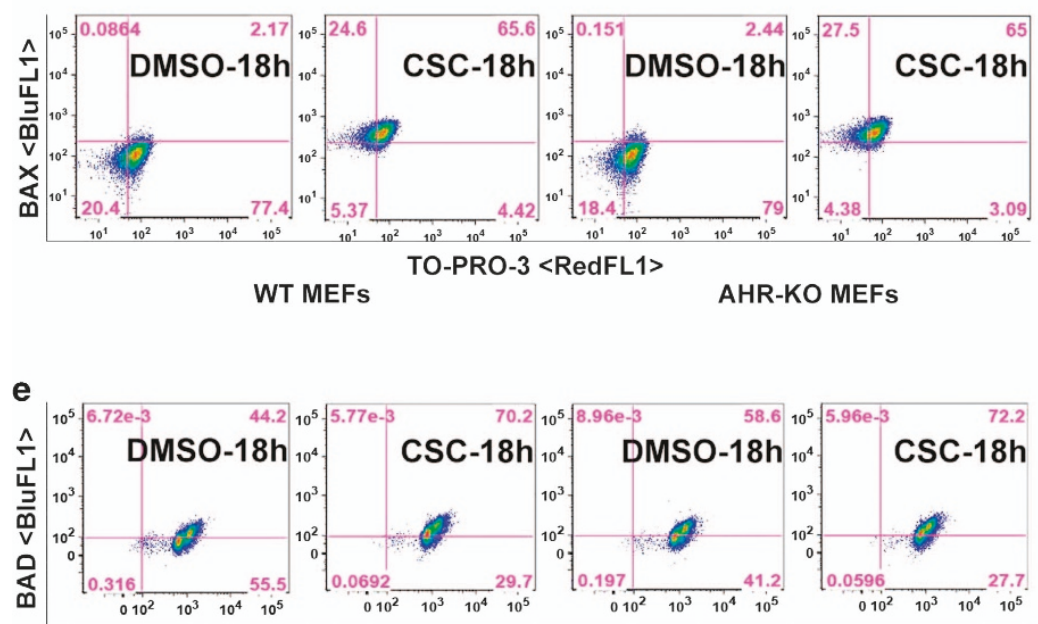

+ Scr-siRNA

TO-PRO-3 <RedFL1>

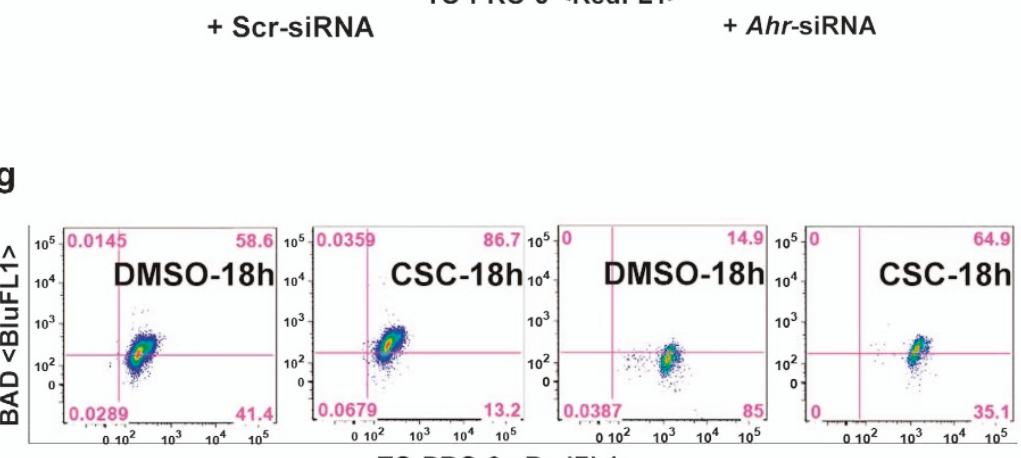

WT MEFs
TO-PRO-3 <RedFL1>

AHR-KO MEFs b
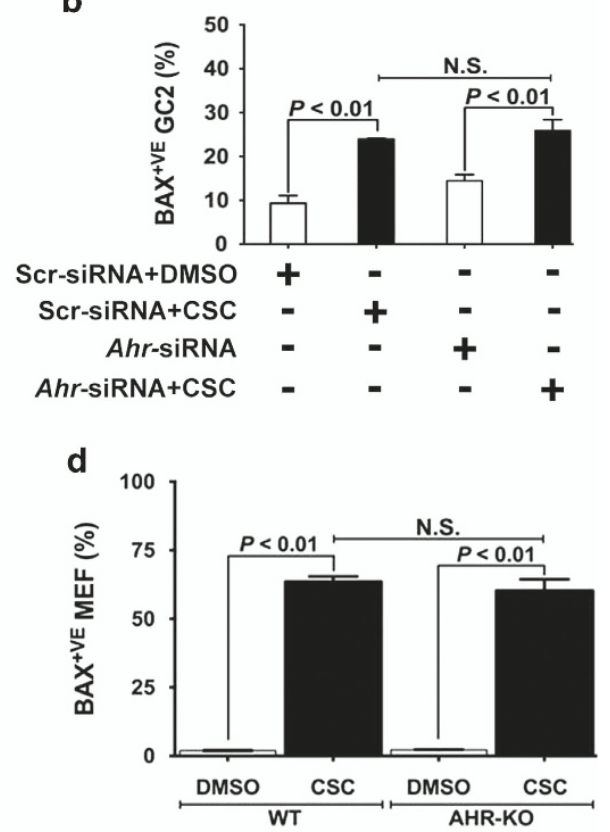

f

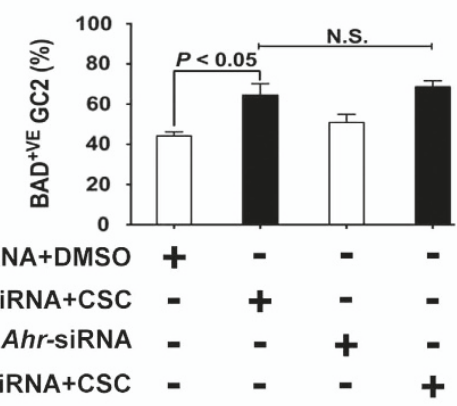

h

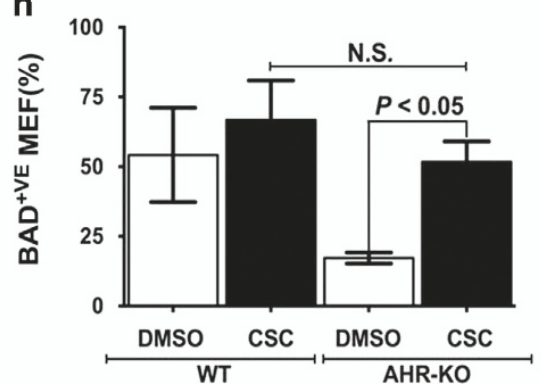

Figure 3. Regulation of proapoptotic proteins by CSC. (a, c, e, and $\mathbf{g}$ ) Representative flow cytometric analyses of (a and e) spermatocytes transfected with scr-siRNA or Ahr-siRNAs and (c and g) WT and AHR-KO MEF cells treated with DMSO or CSC for $18 \mathrm{~h}$ and then stained with (a and $\mathbf{c}$ ) anti-BAX (BluFL1) or (e and $\mathbf{g}$ ) anti-BAD (BluFL1) antibody and counter-stained with TO-PRO-3 (RedFL1). Percentages of doublepositive cells are indicated in the upper right quadrants. (b, $\mathbf{d}$, $\mathbf{f}$ and $\mathbf{h}$ ). Histograms present the mean percentages of double-positive spermatocytes and MEFs from three independent experiments, each assayed in triplicate, \pm S.E.M.

and to assess the role of $A H R$, we performed terminal deoxynucleotidyl transferase dUTP nick end labeling (TUNEL) in CSC-exposed spermatocytes. As expected, CSC significantly increased the number of TUNEL-positive cells. Knockdown of Ahr expression also increased DNA damage, but $A h r$ knockdown and CSC exposure together were not additive (Figures $4 a$ and b). However, pretreatment with the AHR antagonist (CH223191, herein referred to as AHR-inh) significantly reduced the CSCmediated increase in TUNEL-positive cells (Figures $4 c$ and $d$ ). These data indicate that, although CSC-mediated DNA damage occurred in the absence of AHR, blocking AHR activation with an inhibitor blunted CSC-induced DNA damage.

Because poly(ADP-ribose) polymerase (PARP) is involved in DNA repair and is activated in response to DNA damage, we measured cleaved PARP-expressing cells by flow cytometry. We found that CSC exposure increased the percentage of spermatocytes expressing cleaved PARP by a moderate but significant amount. When $A h r$ expression was knocked down, an even higher percentage of CSC-treated spermatocytes expressed cleaved PARP (Figures $4 \mathrm{e}$ and $\mathrm{f}$ ). However, we found an equal percentage 
a

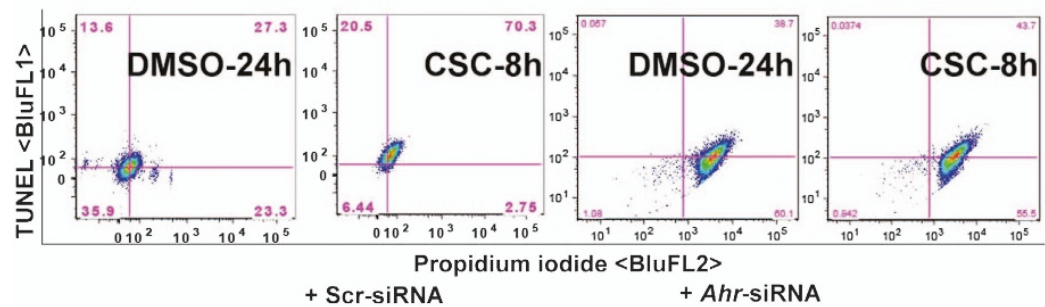

C

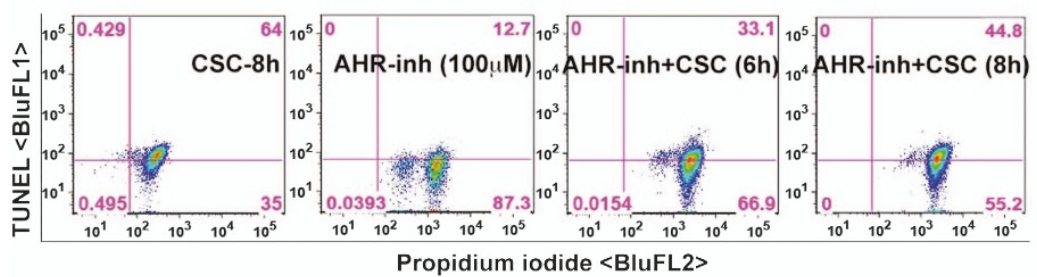

e

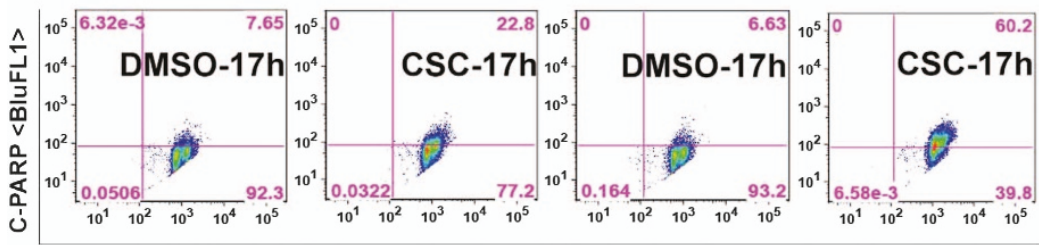

+ Scr-siRnA

TO-PRO-3 <RedFL1>

+ Ahr-siRNA b
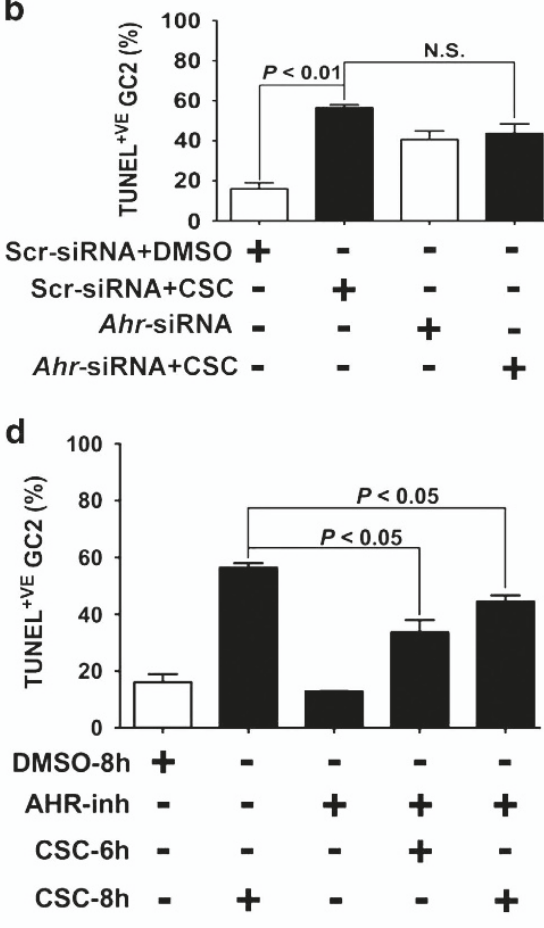

f

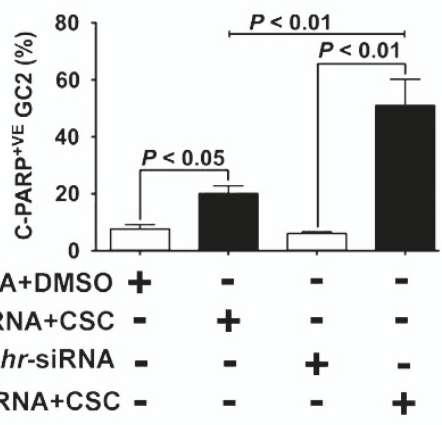

g

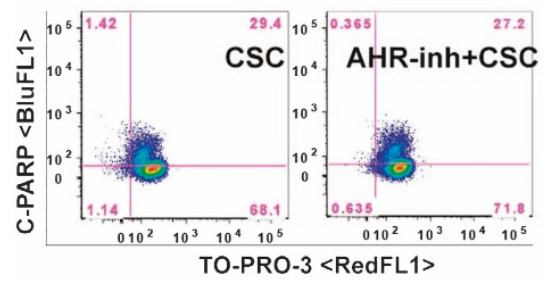

h

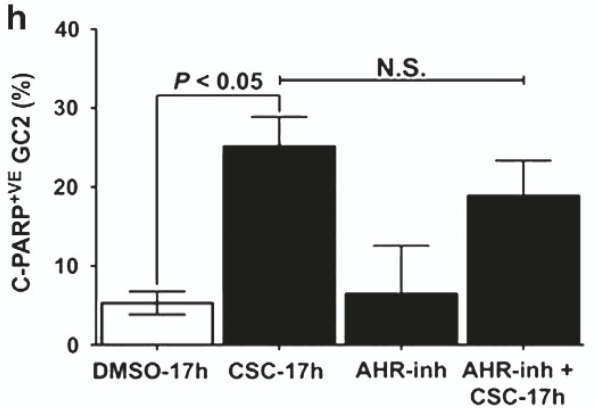

Figure 4. CSC exposure causes DNA fragmentation and cleavage of PARP in spermatocytes. (a and e) Representative flow cytometric analyses of spermatocytes transfected with scr-siRNA or Ahr-siRNAs and then treated with DMSO or CSC (40 $\mu \mathrm{g} / \mathrm{ml}$ ) for (a) $8 \mathrm{~h}$ before TUNEL (BluFL1) and propidium iodide staining (BluFL2) or (e) $17 \mathrm{~h}$ before staining with anti-cleaved PARP antibody (BluFL1) and TO-PRO-3 (RedFL1). (c and g) Representative flow cytometric analyses of spermatocytes treated with CSC, AHR-inh, or both for $8 \mathrm{~h}$ before (c) TUNEL (BlurFL1) and propidium iodide staining (BluFL2) or (g) staining with anti-cleaved PARP antibody (BluFL1) and TO-PRO-3 (RedFL1). Percentages of double-positive cells are indicated in the upper right quadrants. (b, d, $\mathbf{f}$, and $\mathbf{h}$ ) Histograms present the mean percentages of double-positive spermatocyte from three or more experiments, each assayed in triplicate, \pm S.E.M.

of cleaved-PARP-expressing cells in the CSC and CSC plus AHR-KO groups (Figures $4 \mathrm{~g}$ and $\mathrm{h}$ ). We conclude that loss of Ahr exacerbated the CSC-mediated increase in the number of cleaved PARP-expressing spermatocytes but that inhibiting AHR neither ameliorated nor exacerbated the CSC-mediated increase in cleaved PARP-expressing cells.
Is CSC-mediated activation of caspase-3/7 requiring AHR?

Caspases promote cell death in response to proapoptotic signals, and activation of caspase- $3 / 7$ is a hallmark characteristic of classic apoptosis. Thus, it was not surprising that the percentage of spermatocytes expressing activated caspase-3/7 significantly increased to $\sim 68 \%$ upon CSC exposure for $18 \mathrm{~h}$. 
b

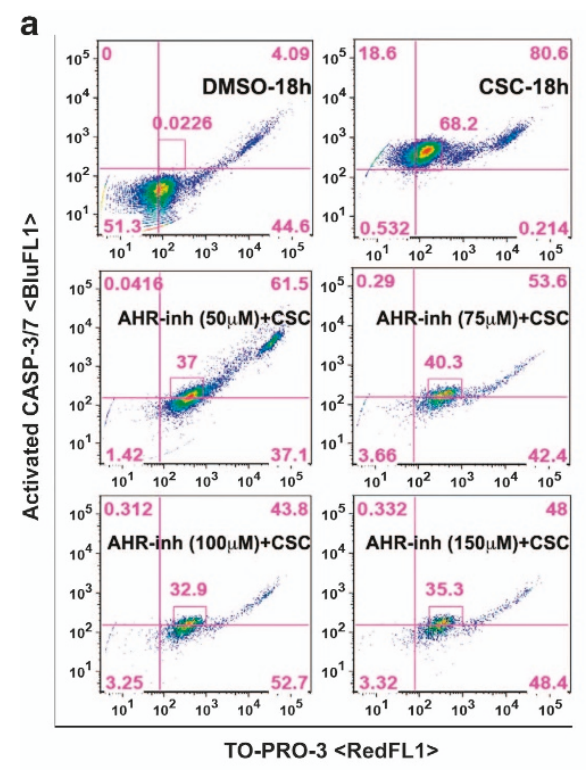

C
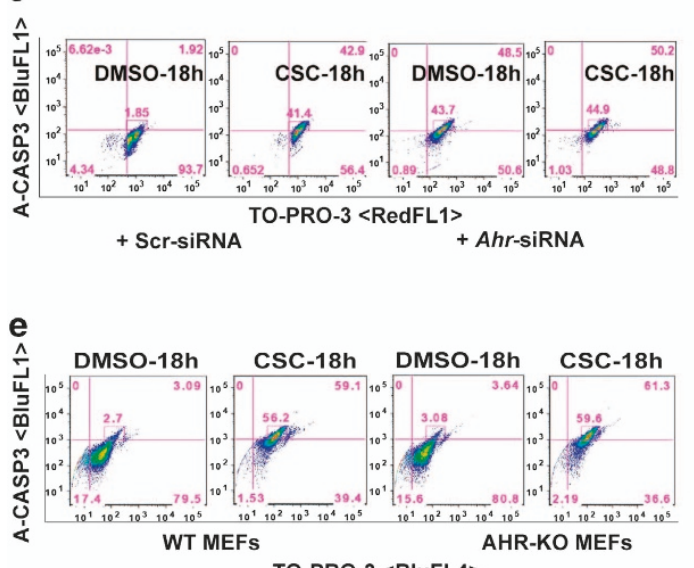

TO-PRO-3 <BluFL4> d

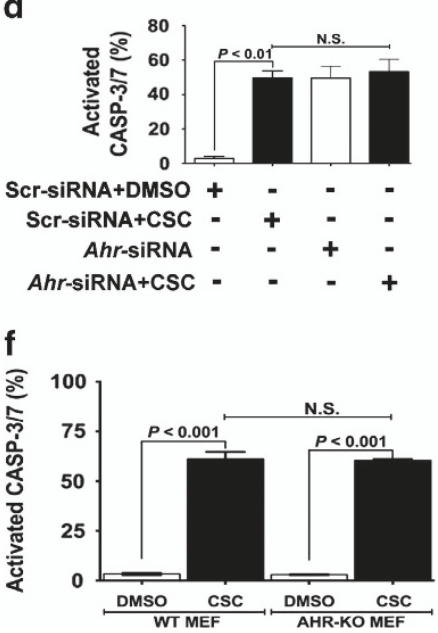

Figure 5. CSC modulated AHR mediates caspase-3/7 activation. (a, c and e). The flow cytometric data represent the distribution of GC-2spd(ts) cells (a) treated with DMSO or CSC $(40 \mu \mathrm{g} / \mathrm{ml})$ for $18 \mathrm{~h}$, AHR-inh alone at different concentrations $(25,50,75,100$ and $150 \mu \mathrm{M})$ or AHR-inh for $1 \mathrm{~h}$ followed by CSC, spermatocytes transfected with scr-siRNA or Ahr-siRNAs and (c) WT and AHR-KO MEF cells (e) treated with DMSO or CSC for $18 \mathrm{~h}$. The treated spermatocytes were labeled by using CellEvent caspase-3/7 green detection reagent for assessing caspase activation and counter-stained with TO-PRO-3. The cell specimens of various groups were evaluated for positive cell populations based on standard compensation calculations on a BD FACSCalibur using FlowJo software (v9.7.5, FLOWJO, LLC., Ashland, OR, USA). The percent difference in caspase- $3 / 7^{+}$cells is shown within the quadrant. $\mathbf{b}, \mathbf{d}$ and $\mathbf{f}$ ). Histogram represents the mean flow cytometric data of percent of caspase- $3 / 7^{+}$ (BluFL1 and RedFL1 double-positive) spermatocyte populations among various treatment groups each assayed in triplicates \pm S.E.M.; $n=3$.

Next, we assessed the role of AHR in expression of caspase-3/7 by treating cells with AHR-inh, which we confirmed did not on its own increase the number of caspase-3/7-positive cells (Supplementary. Figure $1 \mathrm{~A}$ and B). Although pretreatment with AHR-inh at low concentrations (10 and $25 \mu \mathrm{M})$ did not prevent CSC-induced caspase-3/7 activation, concentrations at $50 \mu \mathrm{M}$ and above significantly reduced the percentage of caspase-3/7positive spermatocytes (Figures $5 a$ and b). By contrast, siRNAmediated knockdown of $A h r$ did not reduce the percentage of CSC-induced caspase-3/7-positive spermatocytes (Figures $5 \mathrm{c}$ and d). Likewise, WT and AHR-KO MEFs treated with CSC had equivalent percentages of caspase-3/7-positive cells (Figures $5 e$ and $\mathrm{f}$ ). These data indicate that, although CSCmediated caspase activation occurred in the absence of AHR, blocking AHR activation with an inhibitor blunted CSC-induced caspase activation.
AHR modulates CSC-induced cell membrane damage during apoptosis

We next asked whether CSC could also induce structural damage to the spermatocyte cell membrane. Thus, we used annexin V staining as a marker for externalization of phosphatidylserine. As seen in Figures $6 a$ and $b$, about $70 \%$ of spermatocytes exposed to CSC were positive for annexin V. We next pretreated cells with the AHR-inh, which we confirmed did not cause an increase in the number of annexin-positive spermatocytes (Supplementary. Figure 2), and found that high doses $(50 \mu \mathrm{M}$ and $150 \mu \mathrm{M})$ significantly reduced the percentage of annexin-V-positive spermatocytes after CSC treatment (Figures $6 a$ and b). However, siRNA-mediated knockdown of $A h r$ did not reduce the percentage of CSC-exposed annexin V-positive cells (Figures $6 c$ and d). Likewise, WT and AHR-KO MEFs treated with CSC had equivalent percentages of annexin-V-positive cells (Figures $6 e$ and $f$ ). 
a

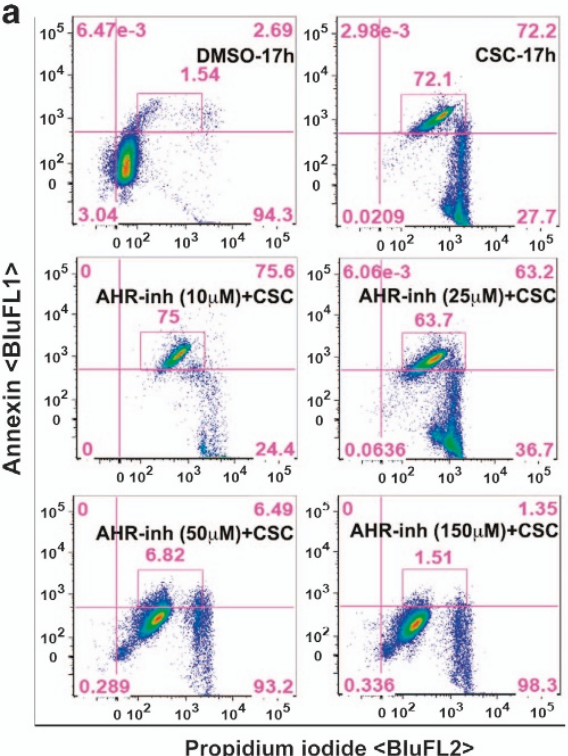

b
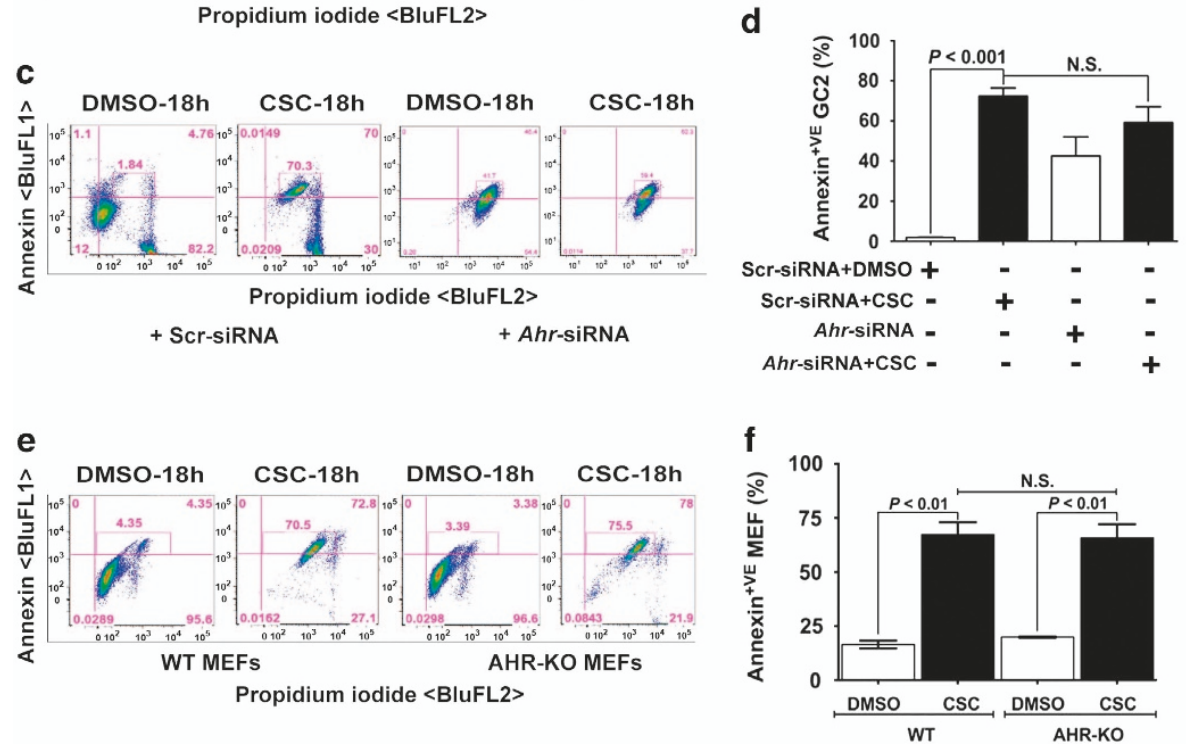

Figure 6. AHR-antagonist prevents CSC-induced cell membrane damage during apoptosis. $\mathbf{a}, \mathbf{c}$ and $\mathbf{e})$. The flow cytometric data represent the distribution of GC-2spd(ts) cells (a) treated with DMSO or CSC $(40 \mu \mathrm{g} / \mathrm{ml})$ for $17 \mathrm{~h}$, AHR-inh alone at different concentrations $(10,25,50$, and $150 \mu \mathrm{M}$ ) or AHR-inh for $1 \mathrm{~h}$ followed by CSC, spermatocytes transfected with scr-siRNA or Ahr-siRNAs and (c) WT and AHR-KO MEF cells (e) treated with DMSO or CSC for $18 \mathrm{~h}$. The treated spermatocytes were labeled with green annexin $V$ Alexa Fluor 488 conjugate and counterstained with PI for detecting externalization of phosphatidylserine. Following staining, the cell specimens of various groups were evaluated for positive cell populations based on standard compensation calculations on a BD FACSCalibur using FlowJo software (v9.7.5, FLOWJO, LLC.). The percent difference in annexin $\mathrm{V}^{+}$cells is shown within the quadrant. $\mathbf{b}$, $\mathbf{d}$ and $\mathbf{f}$ ). Histogram represents the mean flow cytometric data of percent of annexin $\mathrm{V}$ and $\mathrm{PI}^{+}$(BluFL1 and BLuFL2 double-positive) spermatocyte populations among various treatment groups each assayed in triplicate \pm S.E.M.; $n=6$.

These data indicate that CSC structurally modifies the spermatocyte cell membrane during apoptosis, and that, whereas this event is not affected by loss of AHR expression, it is abrogated by inactivation of the AHR pathway.

Blocking activation of MAPKs does not prevent CSC-induced membrane damage

Given our previous study demonstrating crosstalk between p38MAPK, ERK-44/42 and $A H R{ }^{19}$ we asked whether pharmacological inhibition of MAPKs could prevent CSC-induced membrane damage. We first confirmed that neither the p38 inhibitor SB203580 nor the ERK inhibitor PD98059 could, on their own, increase the percentage of annexin-V-positive spermatocytes
(Supplementary Figure 3). Pretreatment with MAPK inhibitors alone or together with AHR-inh could not prevent the externalization of phosphatidylserine in spermatocytes and thus the membrane damage (Figures $7 a$ and $b$ ). These data ruled out the possibility of direct participation of MAPKs in membrane damage while implicating the specificity of AHR pathway in apoptosis.

\section{DISCUSSION}

In this study, we tested the hypothesis that inactivation of AHR could prevent CSC-mediated cell death in the spermatocyte cell line GC-2spd(ts). Our data demonstrate that CSC exposure activated intrinsic pathway of apoptosis via both AHRdependent and -independent mechanisms. These studies 


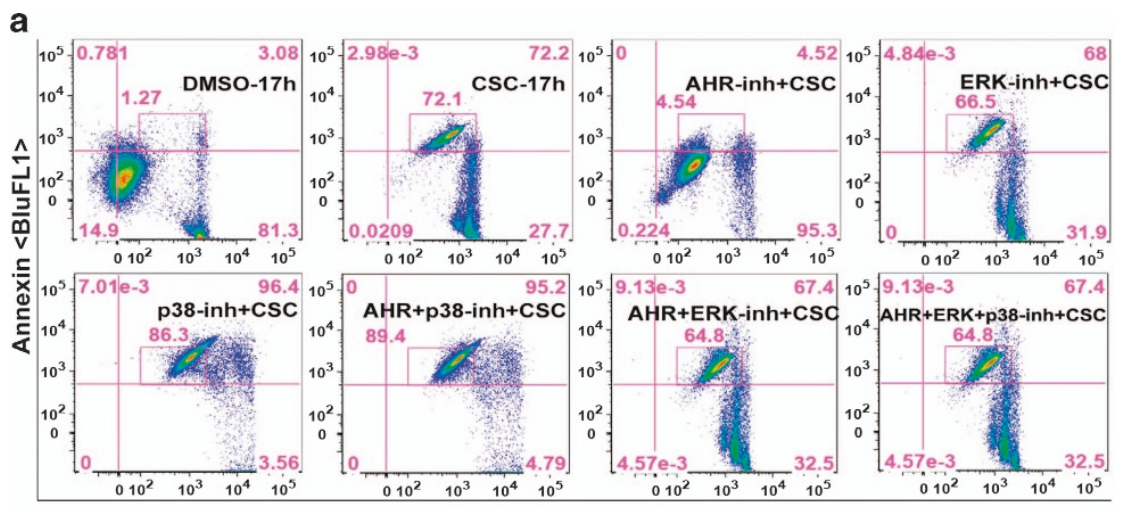

Propidium iodide <BluFL2>

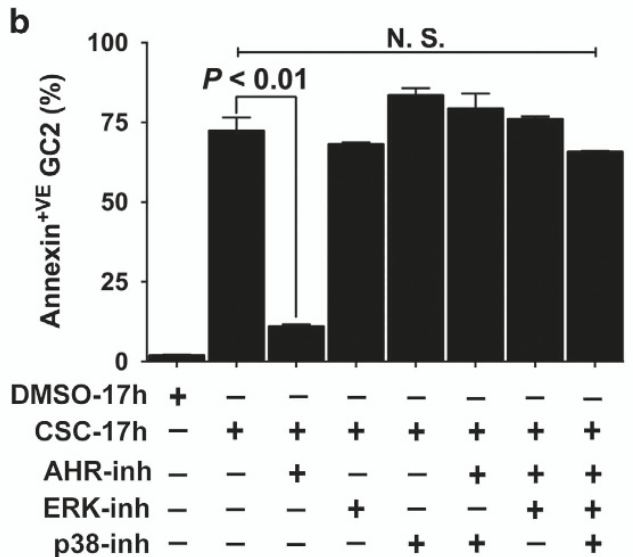

Figure 7. Inactivation of MAPKs does not prevent CSC-induced membrane damage. (a and $\mathbf{b})$. Spermatocytes were exposed to DMSO (0.1\%) or CSC $(40 \mu \mathrm{g} / \mathrm{ml})$ for $17 \mathrm{~h}$. In the antagonists treatment groups, the cells were first pretreated with AHR or MAPK inhibitors or together for $1 \mathrm{~h}$ followed by exposure to CSC for $17 \mathrm{~h}$ (a). The percentage of cells segregated following co-staining with annexin V alexa fluor 488 and PI was determined by FACS analysis using FlowJo software (v9.7.5, FLOWJO, LLC.) as described under materials and methods. The representative histogram demonstrates the distribution of spermatocytes at $17 \mathrm{~h}$. The percent difference in annexin $\mathrm{V}^{+}$cells is shown within the quadrant. (b) Histograms represent the mean flow cytometric data from DMSO-, CSC- or antagonists pretreated samples at $17 \mathrm{~h}$ of more than three independent experiments, each assayed in triplicate \pm S.E.M. $n=4$.

revealed differential expression and activation of antiapoptotic and proapoptotic effector molecules under Ahr suppressed and Ahr-null conditions. Our approach adapting pharmacological intervention of AHR cascade by using $\mathrm{CH} 223191$ substantially decreased the susceptibility of CSC-induced GC-2spd(ts) from initiating apoptotic responses such as caspase activation, DNA damage and membrane alteration.

Fibroblasts and epithelial cells like GC-2spd(ts) are sensitive to the oxidative properties of CS. Our data demonstrating the generation of free oxygen radicals both in the cytoplasm and mitochondria of spermatocytes by the constituents of CSC complement our previous study ${ }^{13}$ and others. ${ }^{20}$ Mitochondrial hyperpolarization $(\Delta \psi \mathrm{m})$ is an early apoptotic event and it has been shown that the activated AHR can regulate mitochondrial function through ATP5a1. ${ }^{21}$ In this study, the lack of change in $\Delta \psi \mathrm{m}$ by $4 \%$ CSC up to $6 \mathrm{~h}$ indicated that the magnitude of mitochondrial oxidative stress was not sufficient enough to alter the membrane potential at the given time point and concentration $(40 \mu \mathrm{g})$. We believe that the exposure of spermatocytes to $4 \%$ CSC for longer duration would alter the $\Delta \psi \mathrm{m}$ and this data correlates to several other studies of AHR ligands exposure in different cell types. ${ }^{22}$ As CSC has forced significant populations of spermatocytes into oxidative stress within $6 \mathrm{~h}$ and the mitochondria is the major intracellular source of ROS, we investigated the involvement of BCL2 family members. Various kinds of cellular stress lead to a shift in mitochondrial membrane potential and outer membrane permeabilization through activation of proapoptotic proteins of the BCL2 family. In contrast, the antiapoptotic members inhibit membrane permeabilization. ${ }^{23}$ In this study, the CSC-exposed spermatocytes under both normal and Ahr-silenced conditions, as well as the WT and AHR-KO MEF expressed equivalent levels of $\mathrm{BCL} 2 \mathrm{~L} 1$ and $\mathrm{BCL} 2$ proteins, corroborating with a previous study in BCL2L1 expression. ${ }^{24}$ These findings suggest that these prosurvival proteins are not under the direct regulation of AHR and their elevation might be an adaptive mechanism for cell survival against growthinhibitory CSC.

Apoptosis is a highly balanced process between proapoptotic and antiapoptotic genes and AHR coordinates between cell proliferation and cell death. ${ }^{15}$ Furthermore, stable AHR KD markedly inhibited growth and promoted apoptosis. ${ }^{25}$ Several exogenous AHR ligands including benzo[a]pyrene in Hepa 1c1c7 cells $^{26}$ and dimethylbenz[a]anthracene in preB cells ${ }^{27}$ have been reported to cause apoptosis. In this study, the CSC-induced increase in proapoptotic $\mathrm{BAX}^{+}$and $\mathrm{BAD}^{+}$populations independent of $A H R$, while in agreement to a previous study by Goode et al., ${ }^{28}$ is contrary to an earlier report demonstrating the direct role of AHR in BAX expression in mouse oocytes. ${ }^{29}$ This discrepancy in regulation can be explained by the observation that the responses to apoptotic stimuli appear to be cell type-and dose-dependent because of the varied expressions of these complex pathways $s^{30}$ and the involvement of oxidative stress in AHR-deficient cells ${ }^{31}$ rather being solely mediated by AHR. 
Our previous studies and others have shown that the constituents of CSC either directly or indirectly regulate genes associated to DNA damage and are responsible for causing DNA strand breaks in spermatocytes under both in vitro and in vivo conditions. $^{13,32}$ We show here that the pretreatment with $\mathrm{CH} 223191$ but not the siRNA-mediated Ahr silencing significantly reduced the temporal increase in CSC-induced DNA strand breaks and the Ahr suppression alone has significantly elevated the $\mathrm{TUNEL}^{+}$population of spermatocytes. These data suggest that the AHR might have a role in regulating the genes involved in the early stages of DNA damage such as Cyp1a1, p21 or repair mechanism as demonstrated in our earlier studies ${ }^{13,33}$ and loss of AHR itself might trigger the signal for DNA damage as reported earlier. ${ }^{34}$ PARP acts as nick sensor during DNA repair and apoptosis $\mathrm{s}^{35}$ and its cleavage serves as a hallmark of classical apoptosis and caspase activation. We observed in this study that the percentage of spermatocytes expressing cleaved PARP was marginal though significant and neither Ahr-silencing nor CH223191 could prevent the CSC-mediated PARP cleavage. However, the marked elevation in CSC-induced $\mathrm{PARP}^{+}$populations among Ahr-suppressed spermatocytes coincides with previous studies demonstrating increased levels of cleaved PARP in AHR-KD epithelial cells. ${ }^{34,36}$

Caspase- 3 is a frequently activated protease indispensable for apoptotic chromatin condensation and DNA fragmentation. ${ }^{37}$ The effect of CS on caspase-3 activity differs significantly among various cell types. ${ }^{38}$ In this study, the marked increase in CSCinduced caspase- $3 / 7^{+}$spermatocytes agrees with an earlier observation, ${ }^{39}$ but differs from others. ${ }^{40}$ This divergence in caspase- 3 activation by CSC can be attributed to the heightened sensitivity of this enzyme to ROS accumulation by high concentration of $\mathrm{CSC}^{41}$ Meanwhile, the dose-dependent inhibition of caspase-3/7 activity by $\mathrm{CH} 223191$ at higher concentrations $(>50 \mu \mathrm{M})$ suggesting the role of AHR and its failure to prevent caspase activation at low dosage is in agreement to an earlier report. ${ }^{42}$ Our effort to further understand AHR regulation of caspase- 3 through siRNA silencing and AHR-KO MEF reveals that the lack of AHR increased basal activity in knockdown spermatocytes, while the addition of CSC might augment caspase activation due to oxidative stress. Our data contradicts previous studies by showing the deficiency in AHR leading to mitochondrial dysfunction and caspase- 3 activation ${ }^{43,44}$ This finding can be explained, however, by the fact that the cells become more susceptible to apoptosis in absence of $\mathrm{AHR}^{45}$ and in the presence of stimuli of the intrinsic pathway. ${ }^{16}$

Cigarette smoking deteriorates the plasma membrane integrity of sperm cells. ${ }^{46}$ Externalization of phosphatidylserine as detected by annexin $\mathrm{V}$ staining is a sensitive, and quantitative approach in apoptosis. Our data here demonstrating the externalization of phosphatidylserine following CSC exposure has been reported in various other cell types. ${ }^{38,47}$ AHR targeted pharmaceuticals are AHR-specific regulators and their antagonistic activities are structure, cell context, response and dose dependent. ${ }^{48}$ As noticed, the cell membrane protective ability of $\mathrm{CH} 223191$ at higher dosage and the maximum amount of apoptotic populations in Ahr-deficient conditions suggests a cytoprotective role of AHR as suggested in other studies. ${ }^{49}$ Our observation is in accordance to a previous study by Rico de Souza et al. $(2011)^{36}$ which demonstrates increased sensitivity of AHR-deficient cells due to reduced expression of super oxide dismutase. In addition, the ability of AHR to regulate apoptosis seems to be a universal phenomenon as AHR-suppressed spermatocytes also displayed increased sensitivity to smoke-induced apoptosis. Even though the pharmacological inhibition of CSC-activated MAPKs abrogates cell cycle arrest, ${ }^{19}$ the failure of MAPK-inh alone or together with $\mathrm{CH} 223191$ in attenuating the CSC-induced membrane alteration in spermatocytes is attributed to the complex free oxygen radicals of $\mathrm{CSC}^{50}$ and the involvement of other signaling mediators. ${ }^{51}$
Thus, the AHR antagonism using inhibitors such as $\mathrm{CH} 223191$ may represent a viable prophylactic therapeutic strategy in the prevention of cell death mediated by CS exposure and other similar fuel burning derived pollutants. The data of the current proposal becomes highly relevant by vividly highlighting the difference between the cell types towards a common physiological process via its molecular response to CS and the molecular divergence of pharmacological inhibition and genetic manipulation. This study collectively suggests that AHR is a viable therapeutic target to prevent CS-induced germ cell death.

\section{MATERIALS AND METHODS}

Cell culture and in vitro CSC and antagonists treatment

The mouse spermatocyte cell line GC-2spd(ts) (ATCC, Manassas, VA, USA), ${ }^{52}$ hereafter referred to as spermatocytes, was grown to $70 \%$ confluence and then serum starved for $24 \mathrm{~h}$. Then, the growth-synchronized cells were treated with $40 \mu \mathrm{g} / \mathrm{ml}$ CS condensate (CSC; in $100 \%$ dimethyl sulfoxide (DMSO); Murty Pharmaceuticals Inc., Lexington, KY, USA; prepared as detailed in our previous study ${ }^{31}$ ) or $0.1 \%$ DMSO for different time durations. In some cases, spermatocytes were pretreated for one hour with various concentrations of the AHR-specific antagonist $\mathrm{CH} 223191$ (2-Methyl-2H-pyrazole-3-carboxylic acid-(2-methyl-4-o-tolyl-azophenyl)amide; referred to herein as AHR-inh; EMD chemicals, Gibbstown, USA) ${ }^{42,53}$ The p38 MAPK inhibitor SB203580 (EMD chemicals, Gibbstown, USA) ${ }^{54}$ was used at $10 \mu \mathrm{M}$, and the ERK-MAPK/MEK1 inhibitor PD98059 (EMD chemicals, Gibbstown, NJ, USA) ${ }^{55}$ was used at $25 \mu \mathrm{M} / \mathrm{ml}$.

\section{Animals and MEF isolation}

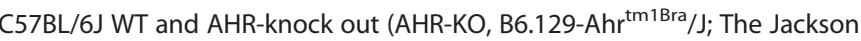
lab, Bar Harbor, ME, USA) mice were housed, bred, and treated experimentally in accordance with the $\mathrm{NIH}$ guidelines for the humane and ethical treatment of animals. All studies were approved by the Animal Studies Committees at Washington University School of Medicine and the St. Louis VA Medical Center. MEFs were isolated as described ${ }^{40}$ from e10.5 embryos and cultured after confirmation of their genotypes.

\section{SiRNA transfection}

Spermatocytes were transfected with siRNAs as previously described. ${ }^{55}$ In brief, spermatocytes grown in 12-well plates were transfected overnight with siRNAs to Ahr or scrambled (scr) siRNAs (Ambion, Carlsbad, CA, USA) at a final concentration of $140 \mathrm{nM}$ in Dulbecco's Modified Eagle Medium. Cells were then treated as described for each experiment and analyzed by flow cytometry with appropriate antibodies. Each transfection assay was repeated a minimum of three times, and the results are shown as the mean \pm S.E.M. of independent experiments.

\section{Flow cytometry and analysis}

Spermatocytes $\left(1 \times 10^{6} / \mathrm{ml}\right)$ exposed to CSC and various inhibitors as described in Results were analyzed on a FACScalibur flow cytometer (Becton-Dickinson, MountainView, CA, USA) as previously described. ${ }^{19}$ FlowJo software (v9.7.5, FLOWJO, LLC.) was used for analysis. To analyze expression patterns, a gate was first drawn around the single-cell populations in a dot plot of forward scatter versus side scatter. A dot plot of BluFL1 versus TO-PRO-3 (RedFL1) / PI (BluFL2) / SYBR 14 (BluFL4) was drawn according to the subclass control, and the quadrant markers were set according to both the vehicle (DMSO) control and the isotype control. The percent of protein/probe-positive (probe ${ }^{+}$) spermatocytes was computed by using the following formula based on the percentage of gated values for the BluFL1 ${ }^{+}$cells: (stimulated - stimulated isotype control) - (unstimulated - unstimulated isotype control). For probes that shift in fluorescence, experimental cells were standardized to vehicletreated cells.

\section{Determination of oxidative stress in GC-2spd(ts)}

Oxidative stress was detected by using CellROX deep red reagent and MitoSOX red mitochondrial superoxide indicator (both from Molecular Probes, Eugene, MN, USA). CellROX exhibits fluorescence (emission maxima at $650 \mathrm{~nm}$ ) upon oxidation by reactive oxygen species, and MitoSOX red (emission maxima at $580 \mathrm{~nm}$ ) detects superoxide in the 
mitochondria of live cells. Spermatocytes were treated with CSC or DMSO for $1 \mathrm{~h}$ and $5 \mathrm{~h}$ as previously reported. ${ }^{13}$ Then, CellROX and MitoSOX reagents were added to a final concentration of $1 \mu \mathrm{M}$ and $5 \mu \mathrm{M}$, for 30 and $10 \mathrm{~min}$, respectively, at $37^{\circ} \mathrm{C}$. The cells were washed with warm buffer as per the manufacturer's protocol, counter-stained with SYBR 14 dye or TOPRO-3 (Molecular Probes; $1: 1,000$ ) for $5 \mathrm{~min}$ at room temperature, and then subjected to flow cytometry.

\section{Evaluation of membrane potential change in mitochondria}

Changes in the membrane potential of mitochondria were detected by using the MitoProbe DiOC2(3) Assay Kit (Molecular Probes) as per the manufacturer's protocol. The GC-2spd(ts) cells exposed to CSC for $6 \mathrm{~h}$ were harvested, washed in warm PBS, incubated with a final concentration of $50 \mathrm{nM} 3,3^{\prime}$-diethyloxacarbocyanine-iodide $\left(\mathrm{DiOC}_{2}(3)\right)$ at $37^{\circ} \mathrm{C}$ for $30 \mathrm{~min}$, and then analyzed by flow cytometry. As a monomer, DiOC2(3) emits green fluorescence, and in a reaction driven by the mitochondrial membrane potential, it converts to a red-fluorescence-emitting dimer.

\section{Analysis of expression of BCL2 family proteins in spermatocytes} Spermatocytes transfected with scr-, or Ahr-siRNA were exposed to DMSO or CSC for $18 \mathrm{~h}$ and analyzed by flow cytometry. The following antibodies were used: rabbit anti-BCL2 (Abcam, Cambridge, UK), rabbit anti-BCL2L1 (Cell Signaling Technology) rabbit anti-BAX (Cell Signaling Technology, Boston, MA, USA), and mouse anti-BAD (Abcam, Cambridge, UK). Anti-BCL2 and anti-BAX rabbit primary antibodies were prelabeled by using zenon rabbit IgG labeling kits (Life technologies) as per the manufacturer's protocol.

\section{Detection of DNA strand breaks in spermatocytes}

To evaluate DNA damage, si-RNA-transfected cells were pretreated with $100 \mu \mathrm{M}$ AHR-inh for $1 \mathrm{~h}$, then exposed to CSC or DMSO for 6 or $8 \mathrm{~h}$. DNA fragmentation was detected by terminal deoxynucleotidyl transferase dUTP nick end labeling (TUNEL) as reported previously ${ }^{56}$ using the in situ cell death detection kit as per the manufacturer (Roche Diagnostics, Indianapolis, IN, USA). In other experiments, spermatocytes were pretreated with $100 \mu \mathrm{M}$ AHR-inh for $1 \mathrm{~h}$, treated with CSC for $17 \mathrm{~h}$, and stained with FITC mouse anti-cleaved Poly(ADP-ribose) polymerase (PARP) antibody (BD Biosciences, San Jose, CA, USA) and counter-stained with TOPRO-3 (Molecular Probes) (1:1,000, $5 \mathrm{~min}$ ) at room temperature. Cells were then analyzed by flow cytometry.

Evaluation of caspase-3/7 activation in spermatocytes and MEFs Spermatocytes were transfected with siRNAs or treated with $25,50,75,100$ and $150 \mu \mathrm{M}$ AHR-inh and then exposed to CSC for $18 \mathrm{~h}$. WT and AHR-KO MEF primary cultures were similarly exposed to CSC. Following CSC treatment, the spermatocytes and MEFs were labeled by using cellEvent caspase-3/7 green flow cytometry assay kit (Molecular Probes) as per the manufacturer's protocol and then analyzed by flow cytometry.

\section{Analysis of annexin $\mathrm{V}$ labeling in spermatocytes and MEFs}

Spermatocytes were treated with DMSO or CSC for $17 \mathrm{~h}$. Then cells were treated with 10, 25, 50, and $150 \mu \mathrm{M}$ AHR-inh $25 \mu \mathrm{M}$ ERK-inh, $10 \mu \mathrm{M}$ p38-inh, or a combination of all three inhibitors for $1 \mathrm{~h}$. WT and AHR-KO MEF cultures exposed to CSC for $24 \mathrm{~h}$, harvested, washed once with $0.1 \%$ BSA-PBS buffer, and then rinsed in $1 \mathrm{X}$ annexin binding buffer $(0.1 \mathrm{M}$ HEPES, pH 7.4; $1.4 \mathrm{M} \mathrm{NaCl} ; 25 \mathrm{mM} \mathrm{CaCl}_{2}$ ), as described previously. ${ }^{57}$ Each $100 \mu \mathrm{l}$ of cell suspension was incubated with $2.5 \mu \mathrm{l}$ of FITC-conjugated annexin V (Molecular Probes), $1 \mathrm{mg} / \mathrm{ml}$ propidium iodide (Invitrogen, Carlsbad, CA, USA), and $50 \mu \mathrm{g} / \mathrm{ml}$ RNaseA (Invitrogen) for $30 \mathrm{~min}$ at $37^{\circ} \mathrm{C}$. Cells were then diluted into $500 \mu \mathrm{l}$ of $1 \times$ annexin binding buffer and analyzed by flow cytometry.

\section{Statistical analyses}

Data are from three or four independent experiments; each assayed in duplicate or triplicate and represented as mean \pm S.E.M. The q-RTPCR data were analyzed by using either two-tailed unpaired $t$-tests or one-way ANOVA (nonparametric) followed by Tukey's multiple comparison test with 95\% confidence intervals. Prism 5.0d (GraphPad, La Jolla, CA, USA) was used, and $P<0.05$ was considered statistically significant.

\section{ACKNOWLEDGEMENTS}

The authors thank Dr. Deborah Frank for her suggestions and scientific editing expertise. We thank the Alvin J. Siteman Cancer Center at Washington University School of Medicine and Barnes-Jewish Hospital in St. Louis, MO, USA, for the use of the Siteman Flow Cytometry Core. The Siteman Cancer Center is supported, in part, by an $\mathrm{NCl}$ Cancer Center Support Grant. This work was supported by the Department of Veterans Affairs, Veterans Health Administration, Biomedical Laboratory Research and Development Award \# I01BX007080 (to DH).

\section{DISCLAIMER}

The views expressed in this article are those of the authors and do not necessarily reflect the position or policy of the Department of Veterans Affairs or the United States government.

\section{COMPETING INTERESTS}

The authors declare no conflict of interest.

\section{REFERENCES}

1 Smoking and infertility: a committee opinion. The Practice Committee of the American Society for Reproductive Medicine. Fertil Steril 2012; 98: 1400-1406.

2 Rodgman A, Perfetti TA. The Chemical Components of Tobacco and Tobacco Smoke. CRC Press, Taylor \& Francis Group: Boca Raton, FL, USA, 2009.

3 Ramlau-Hansen $\mathrm{CH}$, Thulstrup AM, Aggerholm AS, Jensen MS, Toft G, Bonde JP. Is smoking a risk factor for decreased semen quality? A cross-sectional analysis. Hum Reprod 2007; 22: 188-196.

4 Viczian M. The effect of cigarette smoke inhalation on spermatogenesis in rats. Experientia 1968; 24: 511-513.

5 Georgellis A, Montelius J, Rydström J. Evidence for a free-radical-dependent metabolism of 7,12-dimethylbenz[a]anthracene in rat testis. Toxicol Appl Pharmacol 1987; 87: 141-154.

6 Saleh RA, Agarwal A, Sharma RK, Nelson DR, Thomas AJ Jr. Effect of cigarette smoking on levels of seminal oxidative stress in infertile men: a prospective study. Fertil Steril 2002; 78: 491-499.

7 Mostafa M. Cigarette smoking and male infertility. J Adv Res 2010; 1: 179-186.

8 Smith $\mathrm{CJ}$, Hansch $\mathrm{C}$. The relative toxicity of compounds in mainstream cigarette smoke condensate. Food Chem Toxicol 2000; 38: 637-646.

9 Georgellis A, Toppari J, Veromaa T, Rydström J, Parvinen M. Inhibition of meiotic divisions of rat spermatocytes in vitro by polycyclic aromatic hydrocarbons. Mutat Res 1990; 231: 125-135.

10 Nagaraj NS, Beckersa S, Mensaha JK, Waigela S, Vigneswaranc N, Zacharias W. Cigarette smoke condensate induces cytochromes P450 and aldo-keto reductases in oral cancer cells. Toxicol Lett 2006; 165: 182-194.

$11 \mathrm{Gu}$ YZ, Hogenesch JB, Bradfield CA. The PAS superfamily: Sensors of environmental and developmental signals. Annu Rev Pharmacol Toxicol 2000; 40: 519-561.

12 Ge C, Ye J, Wang Q, Zhang C, Yang J, Qian G. Polycyclic aromatic hydrocarbons suppress meiosis in primordial germ cells via the AHR signaling pathway. Toxicol Lett 2012; 210: 285-292.

13 Esakky P, Hansen DA, Drury AM, Moley KH. Cigarette smoke condensate induces aryl hydrocarbon receptor-dependent changes in gene expression in spermatocytes. Reprod Toxicol 2012; 34: 665-676.

14 Hansen DA, Esakky P, Drury AM, Lamb L, Moley KH. The aryl hydrocarbon receptor is important for proper seminiferous tubule architecture and sperm development in mice. Biol Reprod 2014; 90: 1-12.

15 Elizondo G, Fernandez-Salquero P, Sheikh MS, Kim GY, Fornace AJ, Lee KS et al. Altered cell cycle control at the G(2)/M phases in aryl hydrocarbon receptor-null embryo fibroblast. Mol Pharmacol 2000; 57: 1056-1063.

16 Park KT, Mitchell KA, Huang G, Elferink CJ. The aryl hydrocarbon receptor predisposes hepatocytes to Fas-mediated apoptosis. Mol Pharmacol 2005; 67: 612-622.

17 Davis JW 2nd, Lauer FT, Burdick AD, Hudson LG, Burchiel SW. Prevention of apoptosis by 2,3,7,8-tetrachlorodibenzo-p-dioxin (TCDD) in the MCF-10 A cell line: correlation with increased transforming growth factor alpha production. Cancer Res 2001; 61: 3314-3320.

18 Fernandez-Salguero PM, Hilbert DM, Rudikoff S, Ward JM, Gonzalez FJ. Aryl-hydrocarbon receptor-deficient mice are resistant to 2,3,7,8-tetrachlorodibenzo-p-dioxin-induced toxicity. Toxicol Appl Pharmacol 1996; 140: 173-179.

19 Esakky P, Hansen DA, Drury AM, Moley KH. Cigarette smoke-induced cell cycle arrest in spermatocytes [GC-2spd(ts)] is mediated through cross talk between Ahr-Nrf2 pathway and MAPK signaling. J Mol Cell Biol 2015; 7: 73-87. 
20 Hoffmann RF, Zarrintan S, Brandenburg SM, Kol A, de Bruin HG, Jafari S et al. Prolonged cigarette smoke exposure alters mitochondrial structure and function in airway epithelial cells. Respir Res 2013; 14: 97.

21 Tappenden DM, Lynn SG, Crawford RB, Lee K, Vengellur A, Kaminski NE et al. The aryl hydrocarbon receptor interacts with ATP5a1, a subunit of the ATP synthase complex, and modulates mitochondrial function. Toxicol Appl Pharmacol 2011; 254: 299-310.

22 Aly $\mathrm{H}$, Domènech $\mathrm{O}$. Aroclor 1254 induced cytotoxicity and mitochondrial dysfunction in isolated rat hepatocytes. Toxicol 2009; 262: 175-183.

23 Cory S, David C, Huang S, Adams JM. The Bcl-2 family: roles in cell survival and oncogenesis. Oncogene 2003; 22: 8590-8607.

24 Vogel CF, Li W, Sciullo E, Newman J, Hammock B, Reader JR et al. Pathogenesis of aryl hydrocarbon receptor-mediated development of lymphoma is associated with increased cyclooxygenase-2 expression. Am J Pathol 2007; 171: 1538-1548.

25 Abdelrahim M, Smith R 3rd, Safe S. Aryl hydrocarbon receptor gene silencing with small inhibitory RNA differentially modulates Ah-responsiveness in MCF-7 and HepG2 cancer cells. Mol Pharmacol 2003; 63: 1373-1381.

26 Lei W, Yu R, Mandlekar S, Kong AN. Induction of apoptosis and activation of interleukin 1beta-converting enzyme/Ced-3 protease (caspase-3) and c-Jun NH2-terminal kinase 1 by benzo(a)pyrene. Cancer Res 1998; 58: 2102-2106.

27 Near RI, Matulka RA, Mann KK, Gogate SU, Trombino AF, Sherr DH. Regulation of preB cell apoptosis by aryl hydrocarbon receptor/transcription factor-expressing stromal/adherent cells. Proc Soc Exp Biol Med 1999; 221: 242-252.

28 Goode GD, Ballard BR, Manning HC, Freeman ML, Kang Y, Eltom SE. Knockdown of aberrantly upregulated aryl hydrocarbon receptor reduces tumor growth and metastasis of MDA-MB-231 human breast cancer cell line. Int J Cancer 2013; 15: 2769-2780.

29 Matikainen T, Perez Gl, Jurisicova A, Pru JK, Schlezinger JJ, Ryu HY et al. Aromatic hydrocarbon receptor-driven Bax gene expression is required for premature ovarian failure caused by biohazardous environmental chemicals. Nat Genet 2001; 28: $355-360$.

30 Beere HM. Death versus survival: functional interaction between the apoptotic and stress-inducible heat shock protein pathways. J Clin Invest 2005; 115: 2633-2639.

31 Senft AP, Dalton TP, Nebert DW, Genter MB, Puga A, Hutchinson RJ et al. Mitochondrial reactive oxygen production is dependent on the aromatic hydrocarbon receptor. Free Radic Biol Med 2002; 33: 1268-1278.

32 Dertinger SD, Silverstone AE, Gasiewicz TA. Influence of aromatic hydrocarbon receptor-mediated events on the genotoxicity of cigarette smoke condensate. Carcinogenesis 1998; 19: 2037-2042.

33 Esakky P, Hansen DA, Drury AM, Moley KH. Modulation of cell cycle progression in the spermatocyte cell line [GC-2spd(ts) Cell-Line] by cigarette smoke condensate (CSC) via arylhydrocarbon receptor-nuclear factor erythroid 2-related factor 2 (Ahr-Nrf2) pathway. Biol Reprod 2014; 90: 1-12.

34 Marlowe JL, Fan Y, Chang X, Peng L, Knudsen ES, Xia Y et al. The aryl hydrocarbon receptor binds to E2F1 and inhibits E2F1-induced apoptosis. Mol Biol Cell 2008; 19: 3263-3271.

35 Soldani C, Bottone MG, Pellicciari C, Scovassi Al. Two-color fluorescence detection of Poly (ADP-Ribose) Polymerase-1 (PARP-1) cleavage and DNA strand breaks in etoposide-induced apoptotic cells. Eur J Histochem 2001; 45: 389-392.

36 Rico de Souza A, Zago M, Pollock SJ, Sime PJ, Phipps RP, Baglole CJ. Genetic ablation of the arylhydrocarbon receptor causes cigarette smokeinduced mitochondrial dysfunction and apoptosis. J Biol Chem 2011; 286: 43214-43228.

37 Porter AG, Jänicke RU. Emerging roles of caspase-3 in apoptosis. Cell Death Differ 1999; 6: 99-104.

38 Vayssier M, Banzet N, Francois D, Bellmann K, Polla BS. Tobacco smoke induces both apoptosis and necrosis in mammalian cells: differential effects of HSP70. Am J Physiol 1998; 275: 771-779.

39 Wang J, Wilcken DE, Wang XL. Cigarette smoke activates caspase-3 to induce apoptosis of human umbilical venous endothelial cells. Mol Genet Metab 2001; 72: 82-88.
40 Wickenden JA, Clarke MCH, Rossi AG, Rahman I, Faux SP, Donaldson K et al. Cigarette smoke prevents apoptosis through inhibition of caspase activation and induces necrosis. Am J Respir Cell Mol Biol 2003; 29: 562-570.

41 Stringer KA, Tobias M, O'Neill HC, Franklin CC. Cigarette smoke extract-induced suppression of caspase-3-like activity impairs human neutrophil phagocytosis. Am J Physiol Lung Cell Mol Physiol 2007; 292: 1572-1579.

42 Choi EY, Lee H, Dingle RWC, Kim KB, Swanson HI et al. Development of novel $\mathrm{CH} 223191$-based antagonists of the aryl hydrocarbon receptor. Mol Pharmacol 2012; 81: 3-11.

43 Baglole CJ, Sime PJ, Phipps RP. Cigarette smoke-induced expression of hemeoxygenase- 1 in human lung fibroblasts is regulated by intracellular glutathione. Am J Physiol Lung Cell Mol Physiol 2008; 295: 624-636.

44 Stolpmann K, Brinkmann J, Salzmann S, Genkinger D, Fritsche E, Hutzler C et al. Activation of the aryl hydrocarbon receptor sensitizes human keratinocytes for CD95L- and TRAIL-induced apoptosis. Cell Death Dis 2012; 3: e388.

$45 \mathrm{Wu}$ R, Zhang L, Hoagland MS, Swanson HI. Lack of the aryl hydrocarbon receptor leads to impaired activation of AKT/protein kinase B and enhanced sensitivity to apoptosis induced via the intrinsic pathway. J Pharmacol Exp Ther 2007; 320: 448-457.

46 Belcheva A, Ivanova-Kicheva $M$, Tzvetkova $P$, Marinov $M$. Effects of cigarette smoking on sperm plasma membrane integrity and DNA fragmentation. Int J Androl 2004; 27: 296-300.

47 Hoshino Y, Mio T, Nagai S, Miki H, Ito I, Izumi T. Cytotoxic effects of cigarette smoke extract on an alveolar type II cell-derived cell line. Am J Physiol Lung Cell Mol Physiol 2001; 281: 509-516.

48 Jin UH, Lee SO, Safe S. Aryl hydrocarbon receptor (AHR)-active pharmaceuticals are selective AHR modulators in MDA-MB-468 and BT474 breast cancer cells. J Pharmacol Exp Ther 2012; 343: 333-341.

49 Barouki R, Coumoul X, Fernandez-Salguero PM. The aryl hydrocarbon receptor, more than a xenobiotic-interacting protein. FEBS Lett 2007; 581: 3608-3615.

50 Zhuang S, Demirs JT, Kochevar IE. p38 mitogen-activated protein kinase mediates bid cleavage, mitochondrial dysfunction, and caspase- 3 activation during apoptosis induced by singlet oxygen but not by hydrogen peroxide. J Biol Chem 2000; 275: 25939-25948.

51 Kuo W, Chena J, Lina H, Chena B, Hsuc J, Wang C. Induction of apoptosis in the lung tissue from rats exposed to cigarette smoke involves p38/JNK MAPK pathway. Chem Biol Interact 2005; 155: 31-42.

52 Wolkowicz MJ, Coonrod SA, Reddi PP, Millan JL, Hofmann MC, Herr JC et al. Refinement of the differentiated phenotype of the spermatogenic cell line GC-2spd(ts). Biol Reprod 1996; 55: 923-932.

$53 \mathrm{Kim}$ SH, Henry EC, Kim DK, Kim YH, Shin KJ, Han MS et al. Novel compound 2-methyl-2H-pyrazole-3-carboxylic acid (2-methyl-4-o-tolylazo-phenyl)-amide (CH-223191) prevents 2,3,7,8-TCDD-induced toxicity by antagonizing the aryl hydrocarbon receptor. Mol Pharmacol 2006; 69: 1871-1878.

54 Dudley DT, Pang L, Decker SJ, Decker SJ, Bridges AJ, Saltiel AR. A synthetic inhibitor of the mitogen activated protein kinase cascade. Proc Natl Acad Sci USA 1995; 92: 7686-7689.

55 Conner DA. Mouse embryo fibroblast (MEF) feeder cell preparation. Curr Protoc Mol Biol 2001; 51: 23.2.1-23.2.7.

56 Pozarowski P, Huang X, Halicka DH, Lee B, Johnson G, Darzynkiewicz Z. Interactions of fluorochrome-labeled caspase inhibitors with apoptotic cells: a caution in data interpretation. Cytometry A 2003; 55: 50-60.

57 Rieger AM, Nelson KL, Konowalchuk JD, Barreda DR. Modified annexin V/propidium iodide apoptosis assay for accurate assessment of cell death. J Vis Exp 2011; 50: e2597.

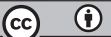

This work is licensed under a Creative Commons Attribution 4.0 International License. The images or other third party material in this article are included in the article's Creative Commons license, unless indicated otherwise in the credit line; if the material is not included under the Creative Commons license, users will need to obtain permission from the license holder to reproduce the material. To view a copy of this license, visit http://creativecommons.org/licenses/ by/4.0/

Supplemental Information accompanies the paper on the Cell Death Discovery website (http://www.nature.com/cddiscovery) 